\title{
Single Crystal X-ray Structural Features of Aromatic Compounds Having a Pentafluorosulfuranyl ( $\mathrm{SF}_{5}$ ) Functional Group
}

\author{
Junyi Du, ${ }^{\mathrm{a}}$ Guoxiong Hua, ${ }^{\mathrm{a}}$ Petr Beier, ${ }^{\mathrm{b}}$ Alexandra M. Z. Slawin and J. Derek Woollins ${ }^{* a}$
}

\begin{abstract}
${ }^{a}$ EastChem School of Chemistry, University of St Andrews, Fife, KY16 9ST, U.K.
${ }^{\text {b}}$ The Institute of Organic Chemistry and Biochemistry of the Czech Academy of Sciences, Flemingovo nam. 2, 16610 Prauge, Czech Republic
\end{abstract}

*Corresponding author. Tel.: (+44)-1334-463384; email: jdw3@st-and.ac.uk

\begin{abstract}
Nine pentafluorosulfuranyl $\left(\mathrm{SF}_{5}\right)$-containing aromatic compounds have been characterized crystallographically. The $\mathrm{SF}_{5}$ group has an umbrella geometry, and the sulfur atom in the $\mathrm{SF}_{5}$ group is in an approximately octahedral coordination environment. All S-F bond lengths [1.572(3) to 1.618(3) $\mathrm{A}]$ are very similar and the C-S-F $F_{a x}$ bond angles $\left[178.94(14)\right.$ to $\left.180^{\circ}\right]$ are very close to each other. The angle of two adjacent $\mathrm{F}_{\text {eq }}$ is approximate to $90^{\circ}$. The intramolecular and intermolecular interactions such as $\mathrm{C}_{\text {aryl }}-\mathrm{H} \cdots \mathrm{F}_{\mathrm{eq}}$, $\mathrm{C}_{\text {aryl- }} \mathrm{H} \cdots \mathrm{O} / \mathrm{N} / \mathrm{F} / \mathrm{Cl}$ interactions, and $\pi$-stacking interactions play a very important role in their three-dimension packing frameworks.
\end{abstract}

Key words: Pentafluorosulfuranyl $\left(\mathrm{SF}_{5}\right)$ group $\cdot$ Aromatic compounds - Single crystal X-ray structure · Intramolecular interactions $\cdot$ Intermolecular interactions

\section{Introduction}

The first organofluorine compound fluoroacetamide was reported in 1896, however, there is no exact information for its preparation [1]. Since then, more attention has been concentrated on the organofluorine compounds and the range of synthetic methods has increased greatly. Fluorocarbon compounds have been used as refrigerants since 1930s [2], and the 'McMahon Act' has promoted the development of organofluorine chemistry since 1949 [3]. The toxicity of fluoroacetate and the biological activity of organofluorine compounds were discovered in 1943 [4]. The high-activity of fluorouracil (5-FU or F5U), which was synthesized in 1950s, has showed that the biological activity can be significantly improved by incorporating fluorine atoms into molecules [5]. In recent years, the research into organofluorine systems has been in a golden period in the fields of biomedicine, pesticide and so on, for example, $20 \%$ of biomedicines and $30 \%$ of pesticides contain at least one 
fluorine atom [6,7]. The applications and importance of organofluorine chemistry have been highlighted recently in several reviews [8-12]. In particular, compounds containing the trifluoromethyl $\left(\mathrm{CF}_{3}\right)$ group or sulfurpentafluoride $\left(\mathrm{SF}_{5}\right)$ group have a key role in organofluorine chemistry due to their special properties such as low surface energy, hydrophobicity, high chemical resistance, high thermal stability and electronegativity. Compounds containing fluorinated groups have been also used as materials, polymers and organic superconductors [13-18]. Although SF5 bearing aromatic compounds have been getting huge attention, their crystal structures have been sparsely reported. Herein, we report the X-ray structures of nine aromatic compounds bearing the $\mathrm{SF}_{5}$ functional group and compare structural similarities and variations with each other or with other known X-ray structures.

\section{Experimental}

Compounds 1-3 were obtained from Apollo Scientific without further purification; compounds 4 [19], 5 [20], 6 [19], 7 [21], 8 [22], and 9 [21] were prepared according to the literature method. The crystal structure data were collected by using a Rigaku SCX-Mini diffractometer (Mercury 2 CCD) at $-148^{\circ} \mathrm{C}$ with graphite-monochromated $\mathrm{Mo}-\mathrm{K}_{\alpha}$ radiation $(\lambda=0.71073 \AA)$ for compounds $\mathbf{1}-\mathbf{4}, \mathbf{6}, 7$ and 9; a Mercury diffractometer (Mercury 70) at $-148^{\circ} \mathrm{C}$ for compound 5, and the St Andrews Robotic diffractometer (Saturn70 CCD) at $-148^{\circ} \mathrm{C}$ [23-25] for compound 8. Intensity data were collected using $\omega$ steps accumulating area detector images spanning at least a hemisphere of reciprocal space. All data were corrected for Lorentz polarization. Absorption effects were corrected on the basis of multiple equivalent reflections by semi-empirical methods. Structures were solved by direct methods and refined by full-matrix least-squares against F2 (SHELXL) [26]. These data can be obtained free of charge via www.ccdc.cam.ac.uk/conts/retrieving.html or from the Cambridge Crystallographic Data Centre, 12 Union Road, Cambridge CB2 1EZ, UK; fax (+44) 1223-336-033; e-mail: deposit@ccdc.cam.ac.uk. CCDC Nos 1497382-1497390.

\section{Results and Discussion}

The chemical structures of nine aromatic compounds involved in this study are shown in Scheme 1. Crystals of compounds 1-9 suitable for X-ray crystallographic analysis were grown by diffusion of hexane into a dichloromethane solution of the compound or by slow evaporation of a dichloromethane solution at room temperature in each case. The details of data collections and 
refinements for 1-9 are listed in Tables S1-S3 (see Supporting Information). Selected distances and angles are listed in Table S4-S7 (see Supporting Information).<smiles>N#Cc1ccc([SbH2])cc1</smiles>

1<smiles>Cc1nc2ccc(S(F)(F)F)cc2nc1C</smiles>

4<smiles>CCOC(=O)Cc1ccc(S(F)(F)F)cc1[N+](=O)[O-]</smiles>

7<smiles>O=C(O)c1ccc(S(F)(F)(F)(F)c2ccccc2)cc1</smiles>

2<smiles>Nc1ccc(S(F)(F)F)cc1O</smiles><smiles>FC(F)(F)c1ccc2c(-c3ccccc3)onc2c1</smiles>

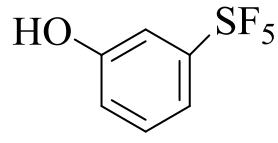

3<smiles>FS(F)(F)c1ccc2nc(-c3ccccc3)c(-c3ccccc3)nc2c1</smiles>

6<smiles>CC(=O)C(Cl)c1cc(S)ccc1[N+](=O)[O-]</smiles>

Scheme 1. The chemical structures of compounds 1-9

Compounds 1-9 crystallised in five different space groups: $C m c m, P 2_{1} / n, R-3, P 2_{1} / c$ and $P-1$. The single crystal X-ray structures of compounds 1-9 are shown in Figure 1. The $S-F_{a x}$ bond lengths in 1-3 are comparable to each other $\{1.588(2) \AA$ in 1, 1.573(3)[1.579(3)] $\AA$ in 2 and 1.607(3)[1.603(3)] $\AA$ in 3 \}, and the values are consistent with that in the similar structures [1.576(2) to 1.600(2) $\AA$ ] [2729]. The $S-F_{\text {eq }}$ bond distances in $\mathbf{1}-\mathbf{3}$ are also close to each other $\{1.582(2) \AA$ in $\mathbf{1}, 1.572(3)$ to 1.590(3) $\AA$ in 2 and 1.590(3) to 1.607(3) $\AA$ in 3, and the longest $\mathrm{S}(1)-\mathrm{F}_{\mathrm{eq}}$ distance [1.607(3) $\AA$, from one of two molecules] in 3 and the shortest one [1.572(3) $\AA$ ] in 2 are observed. The S-C bond distances [1.795(4) to 1.823(4) $\AA$ ] in $\mathbf{1}-\mathbf{3}$ fall in the range of 1.785(3) to 1.812(3) $\AA$ which are comparable to similar structures [27-29]. The C-S-Feq angles in 2 [92.00(16) to 92.81(16) ${ }^{\circ}$ ) and in 3 [92.06(15) to $\left.92.97(15)^{\circ}\right]$ are also similar to each other. The subtle differences in the bond lengths and angles suggests that the environment of $\mathrm{SF}_{5}$ group is almost identical, indicating structural stability of the $\mathrm{SF}_{5}$ group. The different substituent group and group number seem to have limited effect on the bond lengths and angles of the $\mathrm{SF}_{5}$ group in the structures of $\mathbf{1}-\mathbf{3}$, although the electron withdrawing groups $(\mathrm{CN}$ and $\mathrm{COOH})$ and the electron donating group $(\mathrm{OH})$ are present.

The single crystal X-ray structures of 4-9 have very similar $S-F_{a x}$ bond distances [1.568(4) to $1.598(7) \AA]$, S-C bond distances [1.794(5) to 1.812(4) $\AA$ ], and S-F $F_{\text {eq }}$ bond distances [1.572(3) to 
$1.618(3) \AA]$ with the $\mathrm{C}-\mathrm{S}-\mathrm{F}_{\mathrm{eq}}$ angles from $91.3(2)$ to $93.50(13)^{\circ}$, being comparable to that in the known pentafluorosulfanyl aryls with one substituted group. The bond lengths of the S-F single bond and the S-C single bond in 4-9 are similar to the reported values for the S-C single bond [1.818(1) $\AA$ ] and the S-F single bond [1.561(2) $\AA$ ] in $\mathrm{SF}_{6}[30]$. The $\mathrm{F}_{\text {eq }}-\mathrm{S}(1)-\mathrm{C}_{\text {aryl }}-\mathrm{C}_{\text {aryl }}$ torsion angles in 4 and 6 are bigger than that in $\mathbf{5 , 7 , 8}$ and $\mathbf{9}$, twisting from 37.70(3) to $52.40(3)^{\circ}$ in $\mathbf{4}$ and $37.70(3)$ to $52.20(2)^{\circ}$ in 6 (Table S7). Two nitrogen atoms deviate 0.004(6) and 0.007(6) A from the C1-C2-C3-C4-C5-C6 mean plane in 4, and 0.011(5) and -0.008(5) $\AA$ in 6. The twisted angles between the $\mathrm{N}(2)-\mathrm{C}(4)-\mathrm{C}(3)-$ $\mathrm{N}(1)-\mathrm{C}(8)-\mathrm{C}(7)$ ring and two phenyl rings in 6 are 54.01(12) and 43.71(12) ${ }^{\circ}$. There are substituted phenyl ring(s) present in the structures of $\mathbf{6}$ and $\mathbf{8}$, the dihedral angles between the $\mathrm{SF}_{5}$-bearing aryl ring plane and two phenyl planes in 6 are $43.68^{\circ}$ and $53.95^{\circ}$, however, the $\mathrm{SF}_{5}$-bearing aryl ring plane in $\mathbf{8}$ is nearly coplanar with the phenyl ring plane with a small deviation of $2.66[3.71]^{\circ}$, indicating the big steric effect of the more substituted phenyl ring on the structural conformation.

The four equatorial fluorine atoms of the $\mathrm{SF}_{5}$ group have an umbrella shape canting toward the fifth axial fluorine atom in all structures of 1-9 as previously reported for the $\mathrm{SF}_{5}$ group [31,32]. The $\mathrm{F}_{\mathrm{ax}}$ and $\mathrm{S}$ atoms in structure of $\mathbf{1}$ are perfectly coplanar with the aryl ring plane. Whilst the observed deviations of $F_{a x}$ and $S$ atoms out of the adjacent aryl ring planes in structures of 2, 3, 4, 5, 7, 8 and 9 range from 0.009 to $0.205 \AA$ and 0.004 to $0.108 \AA$, respectively. One exception is the structure of 6 , the $S$ atom is coplanar with the aryl ring plane and the $F_{a x}$ atom is $0.007 \AA$ out of this aryl ring plane. The results may explain the relatively high dipole moment of the aromatic pentafluorosulfanyl group $\mathrm{SF}_{5}$ resulting in an additional component to the overall dipole moment in the direction of the long molecular axis [33].
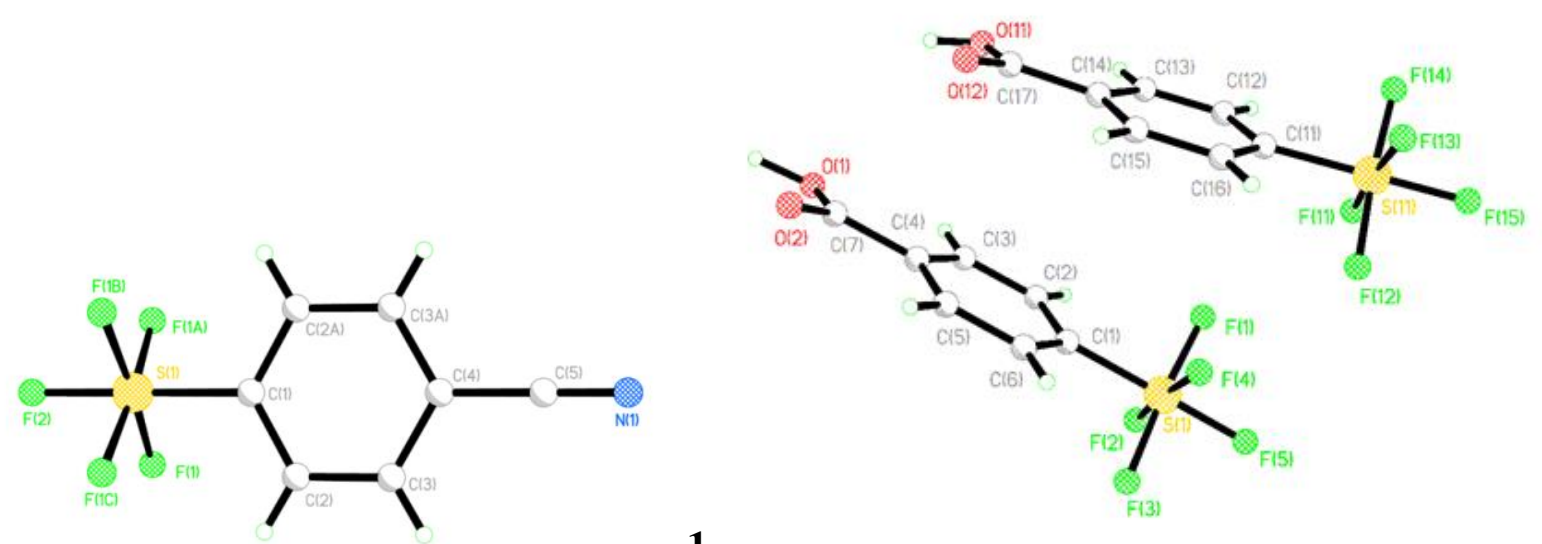

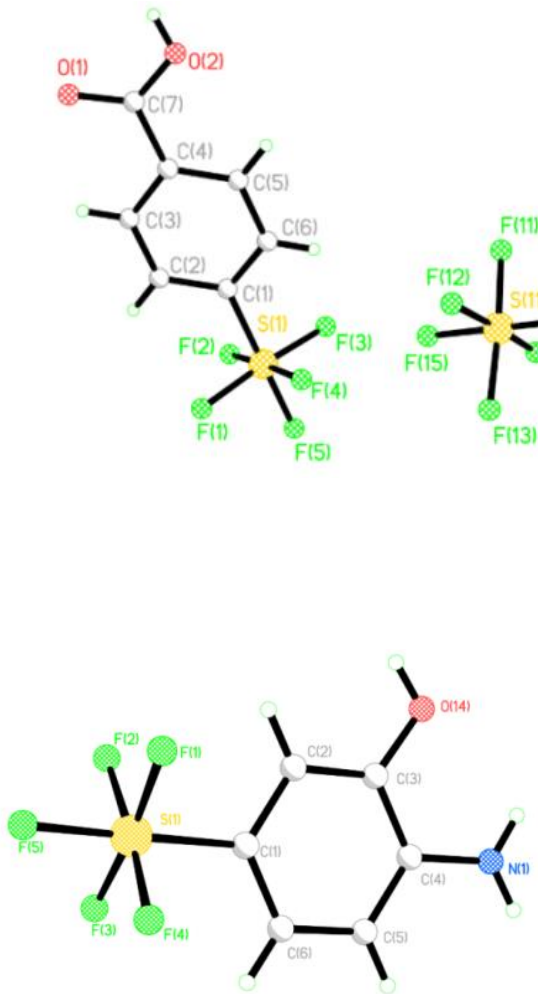

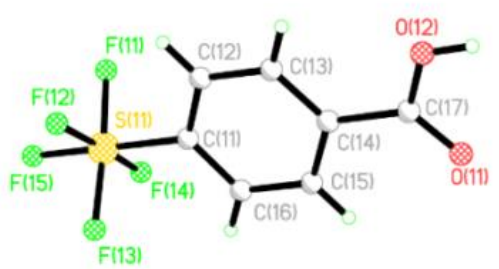

3

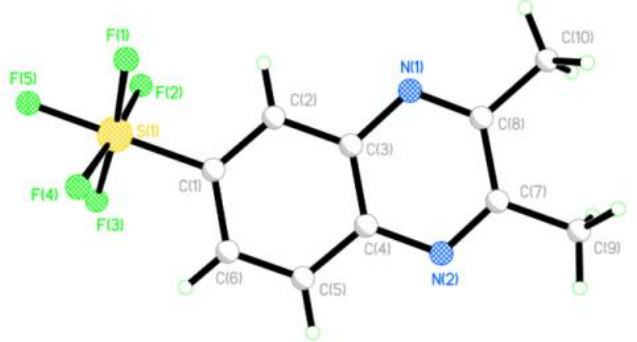

4

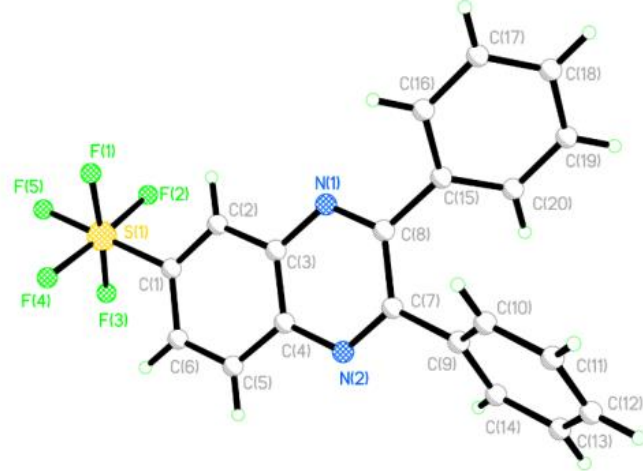
6
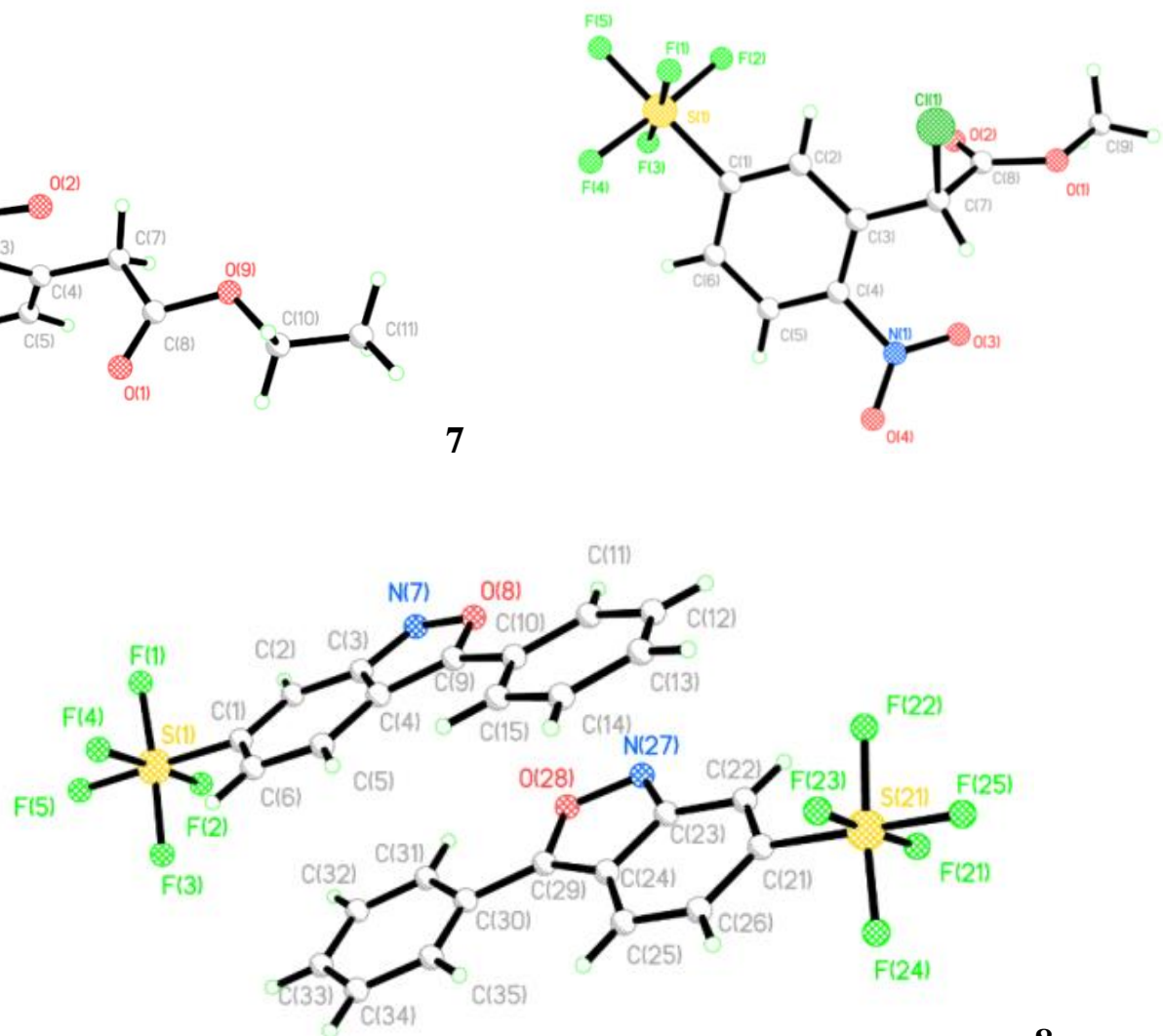

8

Figure 1. X-ray single crystal structures of compounds 1-9

Intramolecular and intermolecular interactions are significant features in pentafluorsulfuranylcontaining aromatic compounds. There are different kinds of interactions in $\mathbf{1}-\mathbf{3}$, including strong 
and weak intramolecular interactions, strong and weak intermolecular interactions and strong $\pi$ stacking interactions. Both intermolecular $\mathrm{C}-\mathrm{H} \cdots \mathrm{F}_{\mathrm{ax}}$ and intermolecular $\mathrm{C}-\mathrm{H} \cdots \mathrm{N}$ interactions are observed with the distances of the $\mathrm{H} \cdots \mathrm{N}$ and $\mathrm{H} \cdots \mathrm{F}_{\mathrm{ax}}$ being 2.883(3) and 2.587(3) $\mathrm{A}$ respectively in 1; these values are close to the sum of Van der Waals Radii (2.700 and 2.550 ̊) (Figure 3). Each layer sheet contains intermolecular interactions. However, no intermolecular interaction is observed between the layers which are parallel with an interlayer distance of 3.432(4) ̊ (Figure 2).
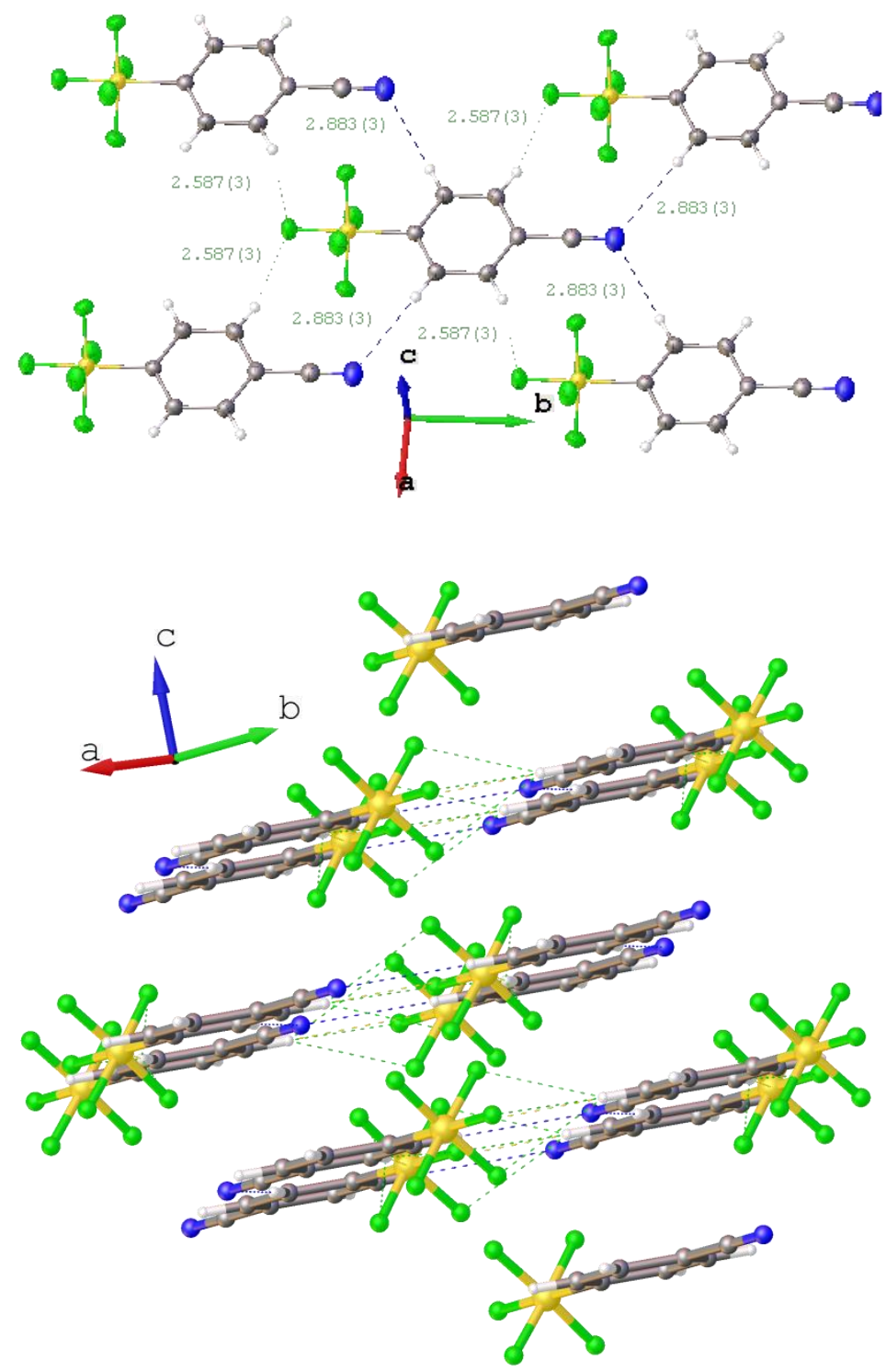

Figure 2. The upper diagram shows possible intermolecular interactions and the lower diagram reveals the layer structure with the intermolecular $\mathrm{C}-\mathrm{H} \cdots \mathrm{F}$ and $\mathrm{C}-\mathrm{H} \cdots \mathrm{N}$ interactions in $\mathbf{1}$.

It is worth noting that two strong intermolecular $\mathrm{O}-\mathrm{H} \cdots \mathrm{O}$ interactions with the $\mathrm{H} \cdots \mathrm{O}$ distances of 1.650(6) and 1.680(6) $\AA$, are observed between 'Head to Head' pairs of molecules in 2 (the upper diagram in Figure 3). The $\mathrm{O}(2) \cdots \mathrm{O}(12)$ and $\mathrm{O}(1) \cdots \mathrm{O}(11)$ distances are 2.615(4) and 2.658(4) $\AA$ 
along with the $\mathrm{O}(2)-\mathrm{H}(2 \mathrm{~A}) \cdots \mathrm{O}(12)$ and $\mathrm{O}(11)-\mathrm{H}(11 \mathrm{~A}) \cdots \mathrm{O}(1)$ angles of $174.0(6)$ and $175.0(6)^{\circ}$; meanwhile, there are two weak intermolecular interactions present as shown in Figure 3. The intermolecular $\mathrm{O}(2)-\mathrm{H}(2 \mathrm{~A}) \cdots \mathrm{O}(11)$ and $\mathrm{O}(11)-\mathrm{H}(11 \mathrm{~A}) \cdots \mathrm{O}(2)$ interactions are almost identical with the $\mathrm{H} \cdots \mathrm{O}$ distances of $2.790(6) \AA$, accompanied by the angles of $132.0(4)$ and $133.0(5)^{\circ}$. Furthermore, the molecular sheets are linked by several weak intermolecular interactions: $\mathrm{H} \cdots \mathrm{S}$ distances range from 3.623(1) to 4.321(1) $\AA, \mathrm{H} \cdots \mathrm{F}_{\text {eq }}$ distances are 2.678(2) and 2.870(2) $\AA$, and $\mathrm{H} \cdots \mathrm{F}_{\mathrm{ax}}$ distance is $2.896(3) \AA$. The layers are packed by the weak intermolecular $\mathrm{C}_{\text {aryl }}-\mathrm{H} \cdots \mathrm{F}, \mathrm{C}_{\text {aryl- }}$ $\mathrm{H} \cdots \mathrm{S}$ and $\mathrm{C}_{\text {aryl }}-\mathrm{H} \cdots \mathrm{O}$ interactions $(\sim 3.00 \AA$ ) as shown in Figure 3 (the lower diagram).
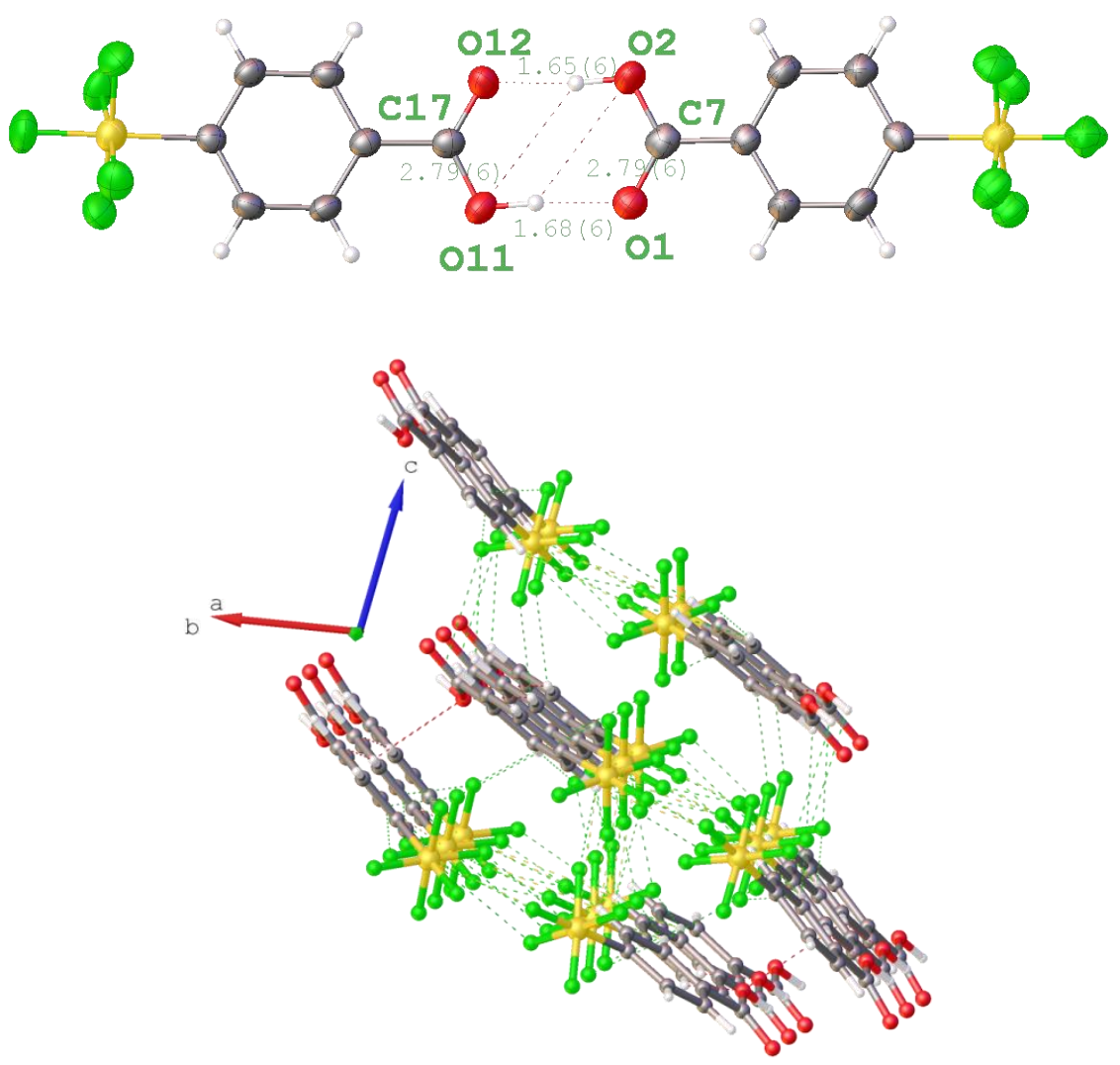

Figure 3. The upper diagram displays clearly intermolecular $\mathrm{C}-\mathrm{H} \cdots \mathrm{O}$ and the lower diagram shows the $\mathrm{C}-\mathrm{H} \cdots \mathrm{F}$ interactions and $\pi$-stacking interactions in $\mathbf{2}$.

The packing network for $\mathbf{3}$ is shown in Figure 4, the 'Head to Head' molecules and 'Tail to Tail' molecules are spirally arranged by the weak intermolecular $\mathrm{C}_{\mathrm{aryl}}-\mathrm{H} \cdots \mathrm{O}$ [2.852(4) and 2.922(4) $\left.\mathrm{\AA}\right]$, $\mathrm{C}_{\text {aryl }}-\mathrm{H} \cdots \mathrm{F}_{\text {eq }}$ [2.551(4), 2.649(3) and 2.929(4) $\AA$ ], $\mathrm{C}_{\text {aryl }}-\mathrm{H} \cdots \mathrm{F}_{\mathrm{ax}}$ [2.619(4) and 2.920(4) $\AA$ ], and $\mathrm{C}_{\text {aryl- }}{ }^{-}$ $\mathrm{H} \cdots \mathrm{S}[3.564(4) \AA]$ interactions. Interestingly, though there is no distinct conventional intramolecular hydrogen bonds in $\mathbf{1}-\mathbf{3}$, the intramolecular interactions between the equatorial fluorine atoms and aromatic hydrogen atoms are found to be very strong, in which the $\mathrm{H} \cdots \mathrm{F}_{\mathrm{eq}}$ distances are close to the sum of the van der Waals radii $(2.550 \AA)$. The intramolecular interaction distance of the $\mathrm{F}_{\text {eq }}$ atoms 
and the ortho-aromatic hydrogen atoms are 2.517(2) $\AA$ in 1. The intramolecular $\mathrm{H} \cdots \mathrm{F}_{\mathrm{eq}}$ interactions with distances of 2.471(3) to 2.648(3) $\AA$ keep the equatorial fluorine atoms staggered relative to the aryl plane in $\mathbf{3}$.

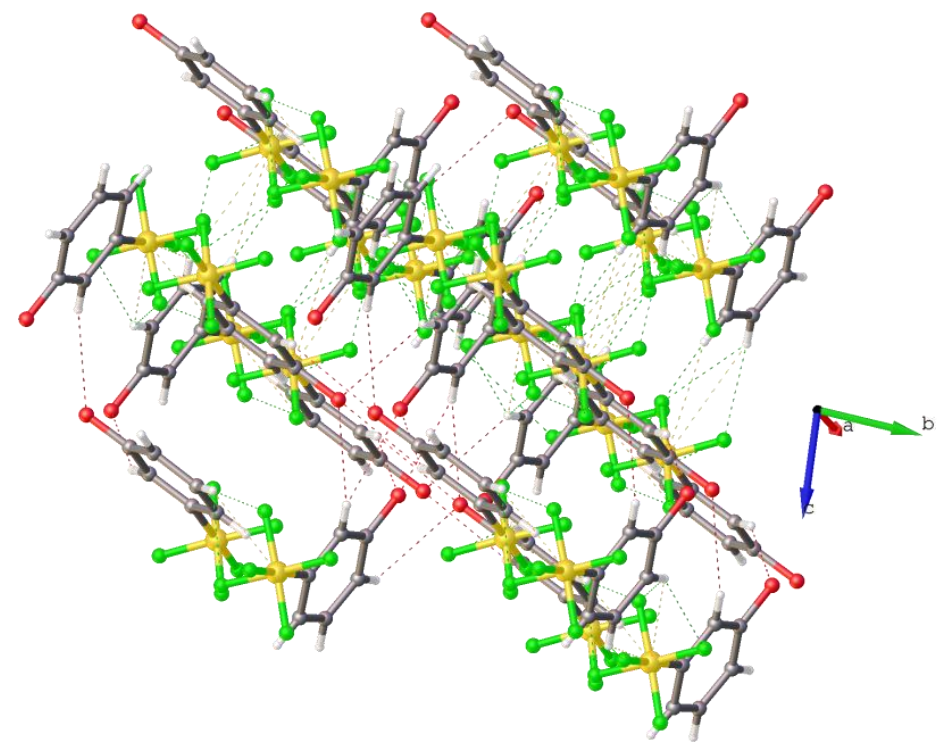

Figure 4. 3-D packing network exhibits the intermolecular $\mathrm{C}-\mathrm{H} \cdots \mathrm{O}$ and $\mathrm{C}-\mathrm{H} \cdots \mathrm{F}$ interactions in 3.

The strong intramolecular $\mathrm{C}_{\text {aryl }}-\mathrm{H} \cdots \mathrm{F}_{\mathrm{eq}}$ interactions might have some influence on the stability of aromatic-SF5 group. In 4, the intramolecular $\mathrm{F}_{\mathrm{eq}} \cdots \mathrm{H}_{\text {aryl }}$ interaction distances are 2.390(3), 2.435(2), 2.619(3) and 2.644(3) $\AA$, and there has also the similar values [2.421(2) to 2.658(2) $\mathrm{A}$ ] in 6. The intramolecular $\mathrm{C}-\mathrm{H}(2) \cdots \mathrm{N}(1)$ interaction distance $[2.560(3) \AA]$ is shorter than that of $\mathrm{C}-\mathrm{H}(5) \cdots \mathrm{N}(2)$ $[2.583(3) \AA]$ in 4 (Figure 5, the upper diagram). However, the intramolecular $\mathrm{C}-\mathrm{H}(2) \cdots \mathrm{N}(1)$ interaction $[2.599(3) \AA]$ is similar to the intramolecular $\mathrm{C}-\mathrm{H}(5) \cdots \mathrm{N}(2)$ interaction $[2.591(3) \AA]$ in 6 (Figure 5, the lower diagram). Furthermore, the $\mathrm{C}_{\text {aryl }}-\mathrm{H} \cdots$ meta-N $[2.687(2) \AA]$ and $\mathrm{C}_{\text {aryl }}-\mathrm{H} \cdots$ para-N $[2.817(3) \AA]$ interaction distances in 6 are considerably longer than that between nitrogen atoms and the relevant $\mathrm{H}_{\text {methyl }}$ atoms [2.450(3) and 2.430(3) $\AA$ ] in 4 .
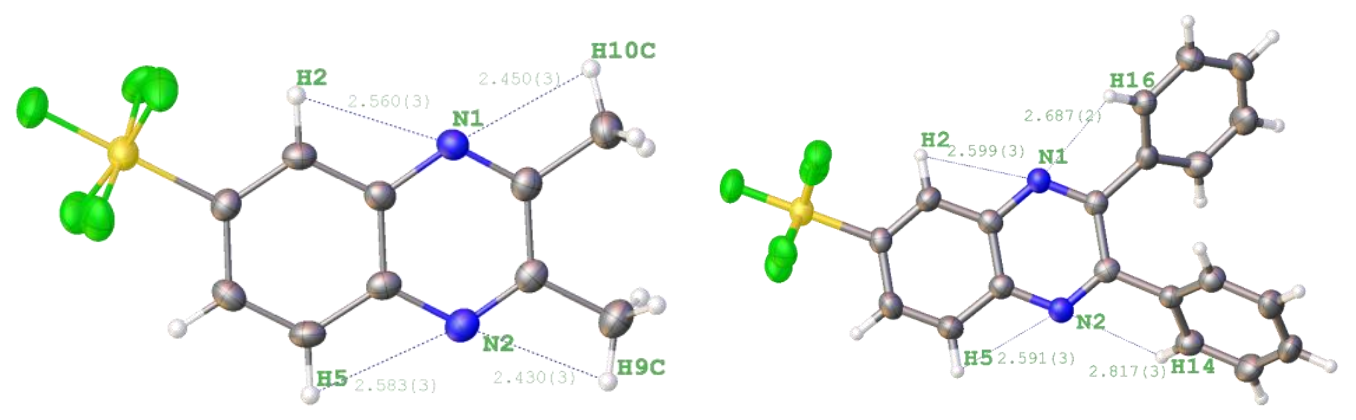
Figure 5. Possible intramolecular interactions between nitrogen and hydrogen in 4 (the left diagram) and 6 (the right diagram).

The intermolecular interactions such as the weak $\mathrm{C}_{\text {methyl }}-\mathrm{H} \cdots \mathrm{N}, \mathrm{C}_{\text {methyl }}-\mathrm{H} \cdots \mathrm{F}$ and $\mathrm{C}_{\text {aryl }}-\mathrm{H} \cdots \mathrm{F}$ interactions can combine in different way to give a variety of packing networks. In 4 , the intermolecular $\mathrm{H} \cdots \mathrm{N}$ interaction distance of 2.744(3) $\AA$ is very close to the sum of Van der Waals Radii [2.700 $\AA$ ] leading to a layer framework; the intermolecular $\mathrm{C}_{\text {methyl }}-\mathrm{H} \cdots \mathrm{F}_{\mathrm{ax}}$ interaction distance of 2.876(2) $\AA$ is longer than the sum of Van der Waals Radii of hydrogen atom and fluorine atoms $\left[\begin{array}{ll}2.550 \AA\end{array}\right]$, but there are other interactions between layers; $\mathrm{C}_{\text {methyl }}-\mathrm{H} \cdots \mathrm{N}$ interaction, intermolecular $\mathrm{C}_{\text {methyl }}-\mathrm{H} \cdots \mathrm{F}_{\text {eq }}$ and $\mathrm{C}_{\text {aryl }}-\mathrm{H} \cdots \mathrm{F}_{\text {eq }}$ interactions $\AA$ which build up the 3-D packing network in a zipper like fashion in 4 (Figure 6, the upper diagram). In 6, the $\mathrm{H} \cdots \mathrm{N}$ distances [2.715(3) and 2.661(2) $\AA$ ] are similar to the $\mathrm{H} \cdots \mathrm{F}_{\mathrm{eq}}$ interaction distance [2.793(2) $\AA$ ]; the intermolecular $\mathrm{C}_{\text {aryl }}-\mathrm{H} \cdots \mathrm{F}_{\mathrm{eq}}$ bonds [2.848(2) and 2.959(2) $\AA$ ] and the $\mathrm{C}_{\text {aryl }}-\mathrm{H} \cdots \mathrm{F}_{\mathrm{ax}}$ interactions [2.852(3) and 2.953(2) $\AA$ ] are almost identical in the packing arrangements due to the two phenyl rings twisting on the quinoxaline ring (Figure 6, the lower diagram).
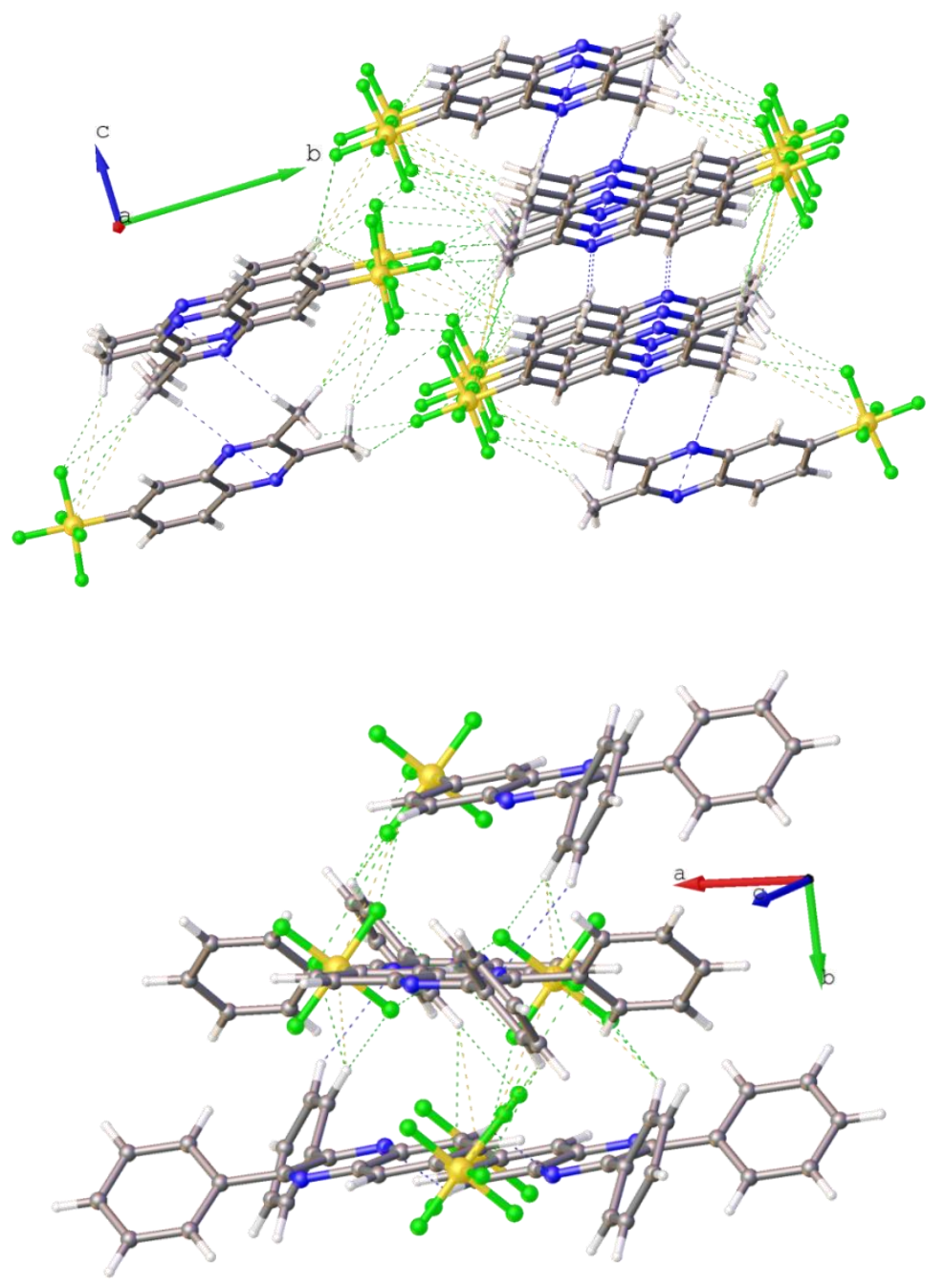
Figure 6. The upper diagram shows the intermolecular $\mathrm{C}-\mathrm{H} \cdots \mathrm{N}$ and $\mathrm{C}-\mathrm{H} \cdots \mathrm{F}$ interactions and $\pi$ stacking interactions in $\mathbf{4}$ and the lower diagram shows the intermolecular $\mathrm{C}-\mathrm{H} \cdots \mathrm{N}$ and $\mathrm{H} \cdots \mathrm{F}$ interactions in $\mathbf{6}$.

The structures of 5, 7, 8 and 9 have $\mathrm{SF}_{5}$-bearing aryl rings with intramolecular $\mathrm{C}_{\text {aryl }}-\mathrm{H} \cdots \mathrm{F}_{\text {eq }}$ interactions [2.385(4) to 2.643(4) $\AA$ ] and intermolecular/intramolecular $\mathrm{O} \cdots \mathrm{H}$ and $\mathrm{N} \cdots \mathrm{H}$ interactions [the $\mathrm{H} \cdots \mathrm{O}$ is $2.364(3) \AA$ with the $\mathrm{N}-\mathrm{H} \cdots \mathrm{O}$ angle of $101.9(3)^{\circ}$ in $\mathbf{5}$; the $\mathrm{H} \cdots \mathrm{N}$ are $2.620(6) \AA$ in $\mathbf{5}$, 2.572(13) $\AA$ in 7, 2.706(5)[2.701(5)] $\AA$ in 8 and 2.557(5) $\AA$ in 9 (Table S7)]. The intramolecular $\mathrm{H}_{\text {phenyl }} \cdots \mathrm{Cl}$ distance $[2.708(18) \AA]$ is shorter than the sum of Van der Waals Radii [3.00 $\AA$ in 9 (Figure 7).

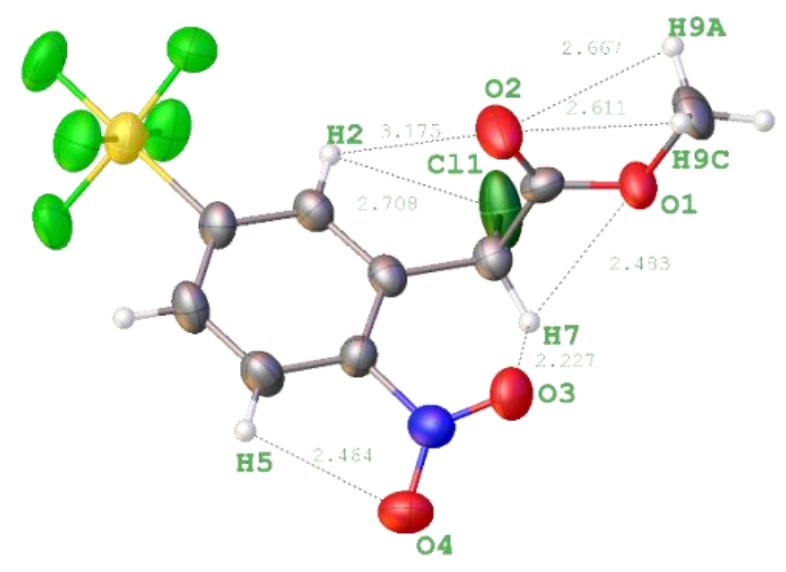

Figure 7. Possible intramolecular $\mathrm{C}-\mathrm{H} \cdots \mathrm{O} / \mathrm{Cl}$ interaction in 9.

A variety of slightly different intermolecular interactions and $\pi$-stacking interactions build up the packing arrangement, and the relevant data are listed in Table S7. The multi-sheeted supramolecular assemblies in $\mathbf{5}$ and $\mathbf{8}$ are formed by the strong intermolecular $\mathrm{C}_{\text {aryl }}-\mathrm{H} \cdots \mathrm{N}$ interactions in conjunction with a series of the weak intermolecular $\mathrm{C}_{\text {aryl }}-\mathrm{H} \cdots \mathrm{F}, \mathrm{C}_{\text {aryl }}-\mathrm{H} \cdots \mathrm{O}$ interactions and $\pi$-stacking interactions (Figure 8). One $\pi$-stacking interaction is observed in the supramolecular assembly with centroid-centroid distance of $3.832 \AA$ in 5 (Figure 8 , the upper diagram). These $\pi$-stacking arrangements are supplemented by a combination of the intermolecular $\mathrm{O}-\mathrm{H} \cdots \mathrm{N}$ [2.063(5) $\AA$ ], $\mathrm{C}_{\text {aryl- }}$ $\mathrm{H} \cdots \mathrm{N}[2.977(4) \AA], \mathrm{C}_{\text {aryl }}-\mathrm{H} \cdots \mathrm{O}[2.543(5) \AA], \mathrm{N}-\mathrm{H} \cdots \mathrm{F}_{\mathrm{eq}}\left[2.429(3)\right.$ and 2.450(3) $\AA$ ] and $\mathrm{C}_{\text {aryl }}-\mathrm{H} \cdots \mathrm{F}_{\mathrm{eq}}$ [2.725(6) $\AA$ ] interactions. Four sets of $\pi$-stacking interactions intersect to create a complex 3-D network in 8 (Figure 8, the lower diagram). The 'zigzag chain' polymeric network is built up with 'Head to Tail' linked by the weak intermolecular $\mathrm{C}_{\text {aryl }}-\mathrm{H} \cdots \mathrm{N}$ and $\mathrm{C}_{\text {aryl }}-\mathrm{H} \cdots \mathrm{F}_{\text {eq }}$ interactions. The $\pi$ stacking interaction between the aryl rings at (x, y, z) and (-x, -y, 2-z) position in $\mathbf{8}$ has a centroidcentroid distance of $3.774 \AA$ with an angle of $2.46^{\circ}$; meanwhile, the $\pi$-stacking interaction between the aryl rings at $(\mathrm{x}, \mathrm{y}, \mathrm{z})$ and $(+\mathrm{x},+\mathrm{y},+\mathrm{z})$ position has a centroid-centroid distance of $3.873 \AA$ with an 
angle of $4.06^{\circ}$; the other two have the centroid-centroid distances of 3.708 and $3.835 \AA$ with the corresponding dihedral angles of 9.02 and 3.19 . Significant intermolecular interactions can be observed in the same layer in 8; the $\mathrm{C}_{\text {aryl }}-\mathrm{H} \cdots \mathrm{N}$ interaction distance is $2.429 \AA$, which is significantly shorter than the sum of Van der Waals Radii of hydrogen atom and nitrogen atom $(2.800 \AA)$. There are also some weak intermolecular $\mathrm{C}_{\text {aryl }}-\mathrm{H} \cdots \mathrm{O}$ and $\mathrm{C}_{\text {aryl }}-\mathrm{H} \cdots \mathrm{F}_{\mathrm{eq}}$ interactions present within one layer.
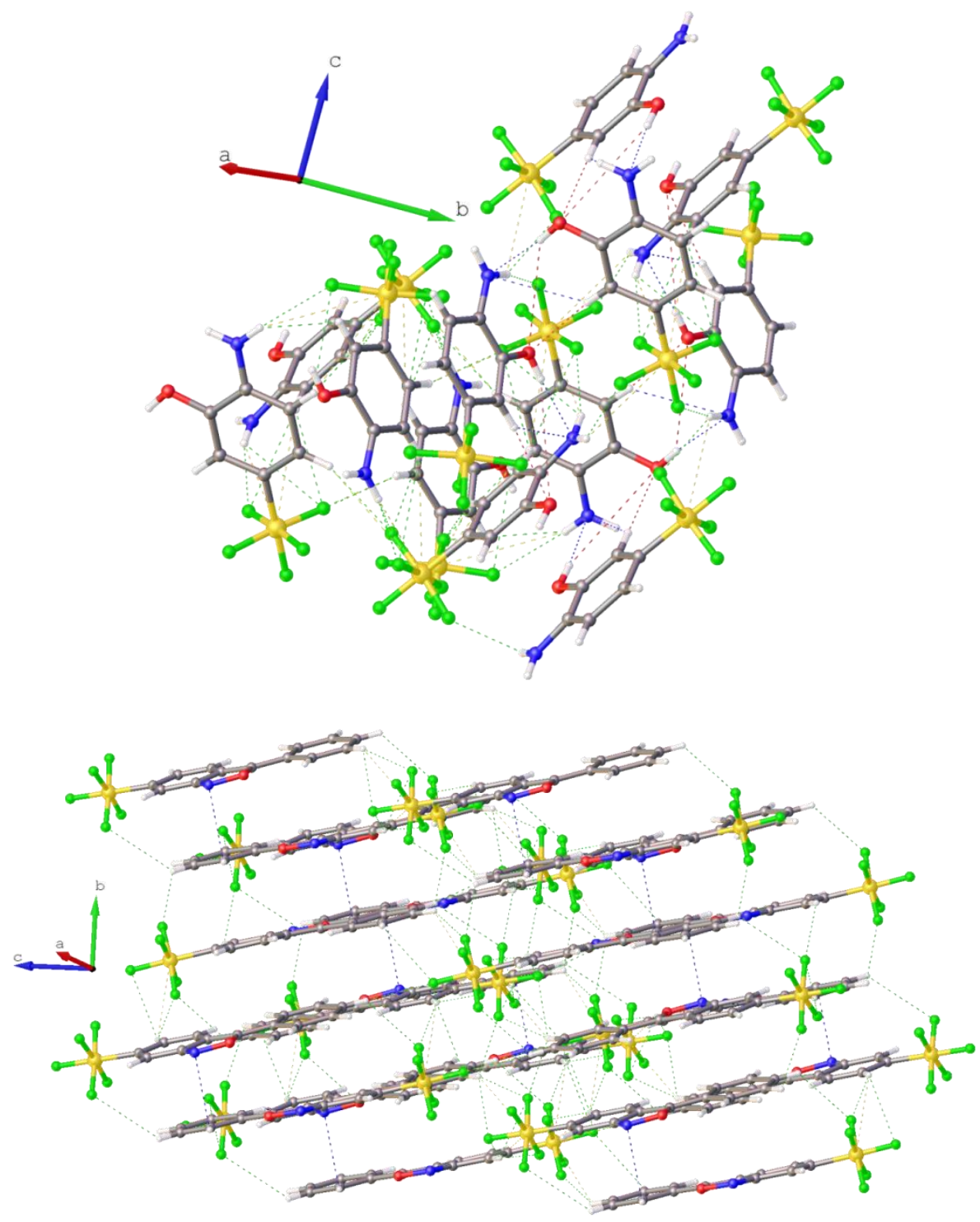

Figure 8. The upper diagram shows the intermolecular $\mathrm{C}-\mathrm{H} \cdots \mathrm{N} / \mathrm{O} / \mathrm{F}$ interactions in $\mathbf{5}$ and the lower diagram shows a 'Zigzag' chain polymeric network built up by the intermolecular C-H $\cdots \mathrm{N}$ and $\mathrm{C}$ $\mathrm{H} \cdots \mathrm{F}$ interactions and $\pi$-stacking interactions in $\mathbf{8}$.

The intermolecular $\mathrm{C}_{\text {aryl }}-\mathrm{H} \cdots \mathrm{O}-\mathrm{N}$ interaction distances [2.470(9) $\AA$ ] in 7 is shorter than that in 9. The intermolecular $\mathrm{C}_{\text {aryl }}-\mathrm{H} \cdots \mathrm{O}(1)[2.645(8)$ to $2.748(8) \AA]$ and $\mathrm{C}_{\text {alkyl }}-\mathrm{H} \cdots \mathrm{F}_{\text {eq }}$ [2.583(8) to 2.767(8) $\AA$ ] interactions are found in 7 (Figure 9, the upper diagram). In 9, there are some weak intermolecular 
$\mathrm{C}_{\text {alkyl }}-\mathrm{H} \cdots \mathrm{O} / \mathrm{Cl}$ interactions and a strong intermolecular $\mathrm{C}_{\text {alkyl }}-\mathrm{H} \cdots \mathrm{O}=\mathrm{C}[2.183(4) \AA]$ interactions present in the layers, meanwhile, the 'Head to Head' and 'Tail to Tail' molecules lead to the packing arrangement in a 'zipper' form, in which the intermolecular $\mathrm{O} \cdots \mathrm{H}$ interaction distances range from $2.737(4)$ to $2.829(5) \AA$ within one layer (Figure 9, the lower diagram).
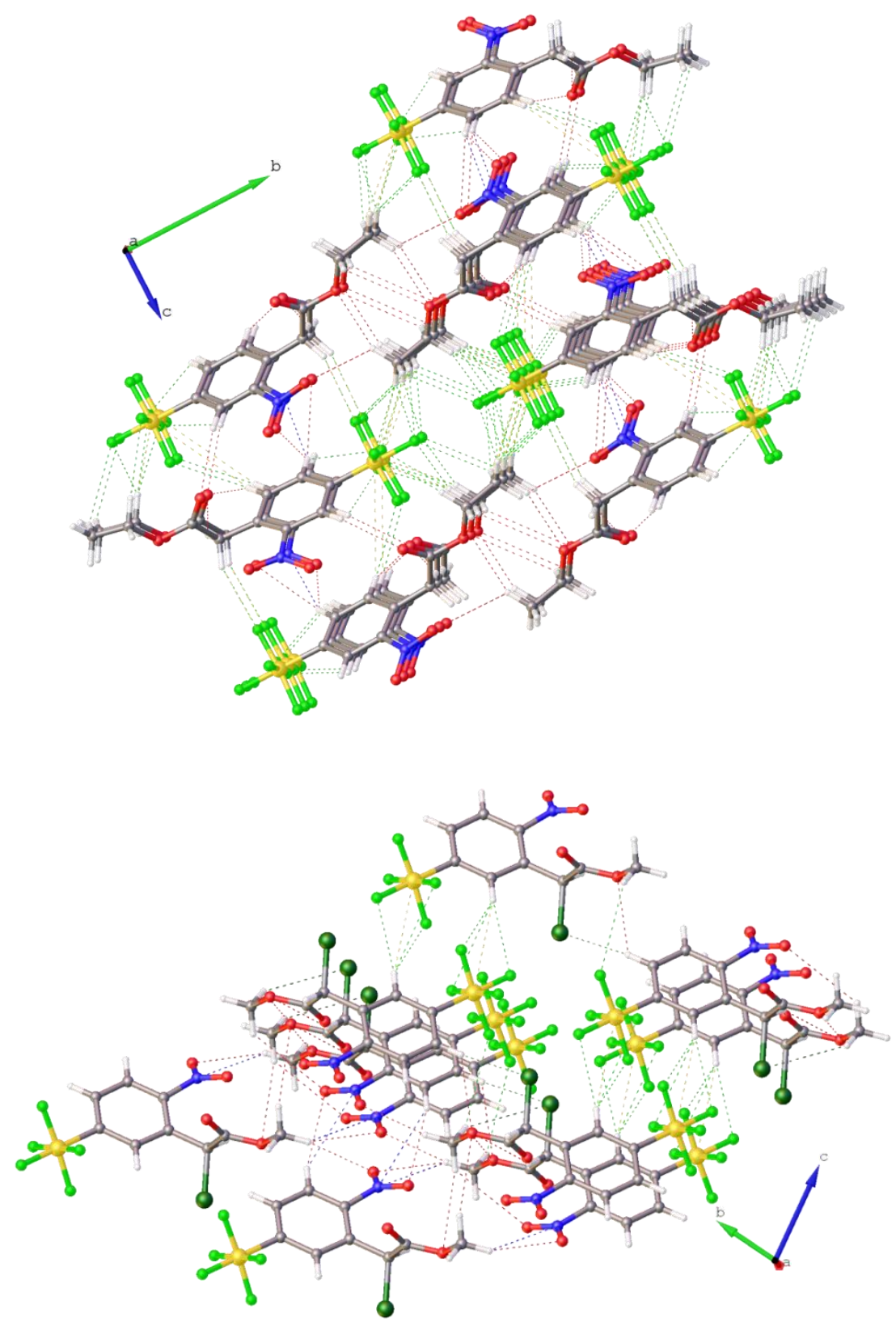

Figure 9. The upper diagram shows the intermolecular $\mathrm{C}-\mathrm{H} \cdots \mathrm{N} / \mathrm{O} / \mathrm{F}$ interactions and $\pi$-stacking interactions in 7 and the lower diagram shows the intermolecular $\mathrm{C}-\mathrm{H} \cdots \mathrm{N} / \mathrm{O} / \mathrm{F} / \mathrm{Cl}$ interactions and $\pi$ stacking interactions in $\mathbf{9}$.

\section{Conclusion}


In summary, a series of organo aromatic compounds bearing the pentafluorosulfuranyl group ( $\left.\mathrm{SF}_{5}\right)$ have been studied crystallographically. The S-F bond lengths in these compounds are very similar ranging from $1.572(3)$ to $1.618(3) \AA$ with very close $C-S-F_{a x}$ bond angles [178.94(14) to $180^{\circ}$ ], and the angle of two adjacent $\mathrm{F}_{\mathrm{eq}}$ is approximate $90^{\circ}$. A range of intramolecular/intermolecular interactions are observed in these structures due to the presence of $\mathrm{O} / \mathrm{N} / \mathrm{Cl} / \mathrm{F}$ atoms in the structures. In particular, the $\mathrm{F}_{\mathrm{eq}} \cdots \mathrm{H}-\mathrm{C}_{\text {aryl }}$ intramolecular interactions [2.385 to $2.703 \AA$ ] fall within the sum of Van der Waals Radii [2.550 ̊]].

\section{Acknowledgements}

We are grateful to the University of St Andrews for financial support.

\section{References}

1. Swarts F (1896) Bull Soc Chim Belg 15:1134-1135

2. Banks RE, Homood E (1979) Organofluorine chemicals and their industry applications, John Wiley \& Sons, London

3. Simons JH, Electrochem J Chem Soc. 95:47-66

4. Marais JSC, Vet J (1943) Sci Anim Ind 18:203-206

5. Heidelerger C, Chaudhuri NK, Danneberg P, Mooren D, Griesbach L, Duschinsky R, Schnitzer RJ, Pleven E, Pleven E, Scheiner J (1957) Nature 79:663-666

6. Purser S, Moore PR, Swallow S, Gouverneur V (2008) Chem Soc Rev 37:320-330

7. Muller K, Faeh C, Diederich F (2007) Science 317:1881-1886

8. Furuya T, Kamlet AS, Ritter T (2011) Nature 473:470-477

9. Allemann O, Duttwyler S, Romanato P, Baldridge KK, Siegel JS (2011) Science 332:574-577

10. Lee E, Kamlet AS, Powers DC, Neumann CN, Boursalian GB, Furuya T, Choi DC, Hooker JM, Ritter T (2011) Science 334:639-642

11. Choi J, Wang DY, Kundu S, Chliy Y, Emge TJ, Krogh-Jespersen K, Goldman A (2011) Science 332:1545-1548

12. Rauniyar V, Lackner AD, Hamilton GL, Toste FD (2011) Science 334:1681-1684

13. Schlueter JA, Geiser U, Wang HH, Kelly ME, Dudek JD, Williams JM, Naumann D, Roy T (1996) Mol Cryst Liq Cryst Sci Technol Sect Mol Cryst Liq Cryst 284:195-202

14. Kirsch P, Bremer M, Taugerbeck A, Wallmichrath T (2001) Angew Chem Int Ed 40:1480-1484

15. Winter R, Nixon PG, Terjeson RJ, Mohtasham J, Holcomb NR, Grainger DW, Graham D, Castner DG, Gard GL (2002) J Fluorine Chem 115:107-113 
16. Smith JA, Distasio RA, Hannah NA, Winter RW, Weakley TJR, Gard GL, Rananavare SB (2004) J Phys Chem B 108:19940-19948

17. Suzuki Y, Hagiwara T, Kawamura I, Okamura N, Kitazume T, Kakimoto M, Imai Y, Ouchi Y, Takezoe H, Fukuda A (2006) Liq Cryst 33:1344-1349

18. Li W, Chen G, Zhang S, Wang H, Yan D (2007) J Polym Sci Part A Polym Chem 45: $3550-3561$

19. Pastyrikova T, Iakobson G, Vida N, Pohl R, Beier P (2012) Eur J Org Chem 2123-2126

20. Beier P, Pastyrikova T (2011) Tetrahedron Lett 52:4392-4394

21. Beier P, Pastyrikova T (2011) J Org Chem 76:4781-4786

22. Beier P, Pastyrikova T (2013) Beilstein J Org Chem 9:411-416

23. Schinor B, Wibbeling B, Haufe G (2013) J Fluorine Chem 155:102-109

24. Ponomarenko MV, Lummer K, Fokin AA, Serguchev YA, Bassil BS, Roschenthaler G (2013) Org Biomol Chem 11: 8103-8112

25. Okazaki T, Laali KK, Bunge SD, Adas SK (2014) Eur J Org Chem 1630-1644

26. Sheldrick GM (2008) Acta Crystallogr A 64:112-122

27. Muller K, Faeh C, Diederich F (2007) Science 317:1881-1886

28. Winter RW, Dodean R, Smith JA, Anilkumar R, Burton DJ, Gard GL (2005) J Fluorine Chem 126:1202-1214

29. Wipf P, Mo T, Geib SJ, Caridha D, Dow GS, Gerena L, Roncal N, Milner EE (2009) Org Biomol Chem 7:4163-4165

30. Berg C, Braun T, Laubenstein R, Braun B (2016) Chem Comm 52:3931-3934

31. Zarantonello C, Guerrato A, Ugel E, Bertani R, Benetollo F, Milani R, Venzo A, Zaggia A (2007) J Fluorine Chem 128:1449-1453

32. Hua G, Du J, Slawin AMZ, Woollins JD (2014) J Org Chem 79:3876-3886

33. Kirsch P, Bremer M, Heckmeier M, Tarumi K (1999) Angew Chem Int Ed 38:1989-1992 